\title{
National Culture and Modern Business Ethics in MNCS in Ghana-An Analysis
}

\author{
Article by Philip Spitta Ansah \\ Business and Management, Texila American University, Guyana \\ E-mail:spitt9@gmail.com
}

\begin{abstract}
This study had the aim of examining the influence that national cultures have on the formulated business ethics and codes of conduct being implemented in multinational corporations. It is an undeniable fact that individual employees who make up the workforce come from different cultural backgrounds and orientations. In the light of this, it became more interesting to find out if their cultural backgrounds affect their ability to adhere to the ethics of the organizations they work for. The focus was on the national culture of Ghana and the imported business ethics by the management of multinational organizations operating in the country. Hofstede's groundbreaking work and the GLOBE expanded scope study remains the largest study to examine national culture with selected countries specifically for the purpose of providing valuable guidance to individuals seeking to work effectively across such differences. The result as put forward by the various research data on this subject especially from Hofstede and the GLOBE shows that the national culture of Ghana does not necessarily affect the implementation and enforcement of the corporate ethics in multinational firms operating in Ghana. On the contrary, most of the multinational organizations come from a very strong and regulated corporate ethics environment established by legal regimes in their home country. It is also worth noting that most of the multinational firms conduct orientation for new employees and occasionally for old staff as well.
\end{abstract}

Keywords: Corporate Business Ethics, National Culture, Ghana, Employee orientation, organizational culture, Multinational corporations.

\section{Introduction}

Business ethics and culture focused research is gaining currency in the light of recent scandals that have rocked many multinational organizations. Employees and external contractors of multinational organizations represent the image of their companies and therefore their actions or inactions have implications. What is acceptable and what is unacceptable is a matter of opinion.

The desire for multinational corporations to be innovative has driven them to seek for rapid expansion of their operations around the globe. As they move into these new territories, there seem to be an increasing demand for a thoughtful approach to dealing with the diverse cultural values of foreign cultures in which they operate with an eye on ethics. The differences in national culture lie in values rather than practice. While, in organizational level, culture differences appear mostly in practice rather than value (ibid). Ybema and Byun (2009) refer to Schneider and Barsoux's (1997) argument that the parent country's culture is often remained in multicultural companies, and the national culture of parent's company is often challenged by the national culture of subordinate company, because of the foreign rule put on it as cited by (Rufei and Jianchao, 2010).

Due to the fact that organizational culture is unique to each organization, the need for clarification of its effects on business ethics practices is critical (Enginoglu, D and Arikan, C. 2016). We live in a globalized village where multinational organizations are confronted with diverse multicultural operational environment with people of different ethnic, tribal, and national origins and identities.

The current global workforce find itself at work surrounded by people of different cultural, religious, social, sexual, educational, philosophical, political, economic, and ethical orientations and persuasions. Business leaders on the hand are also under constant scrutiny from regulators to ensure proper ethical behavior by the organization as a whole. According to Enginoglu and Arikan (2016), ethical business practices are praised ever more in today's business environment. However, Andrews 
and Hunt (2011) assert that certain gaps in the form of "deceptive advertising, high pressure selling, unsafe products, irresponsible use of credit cards, bribes, unsafe working conditions" still exists in certain organizations around the world.

Considering that several multinational and transnational companies operating in Ghana in the likes of Shell petroleum, MTN, PWC, Ernst \& Young, Airtel, Unilever, Barclays, Roche, Pfizer, GlaxoSmithKline, Deloitte, KPMG, AngloGold Ashanti, Newmont Gold, Stanbic Bank, Zenith Bank, British Airways, Kenya Airways, Emirates Airlines etc., have diverse backgrounds, the need to orient employees becomes more important for the success of these organizations.

From the list above, one can easily see the diverse nature of these MNCs especially considering the culture of their home countries. Enginoglu and Arikan (2016) posit that ethics is no longer an area of interest just for the sake of it but also with its direct and indirect influence on measurable company performance levels. Smith and Hume (2005) in their quantitative study, reported significant cultural effects on ethical responses. It therefore supports the idea that Ghanaians and other nationals working with these organizations have to be properly oriented in order to make sure they are well informed about their ethical responsibilities.

We live in a world where what we sometimes think is good or bad is usually determined by the way we are influenced culturally. Also, there is a growing awareness of multinational corporations to have and maintain a better focus on an ethical conduct that goes beyond the strict legal interpretation of laws in their host country. Multinational companies are usually more noticeable and more so if they originate from USA or more advanced European countries. Due to this and sometimes by their magnitude, there is a greater need for a formal ethical code of conduct for its employees.

On the basis of the above arguments, the challenge for these MNCs is to have the ability to develop and reconcile the conflicting forces of:

- Universally acceptable ethical code

- Cultural relativism (i.e., the need to adapt or customize ethics to local culture)

- Dealing with undue advantages enjoyed by companies from unethical countries who end up gaining unfair competitive edge.

- Lack of harmonization in country code of ethics across the globe

In the light of this, this paper seek to undertake an analysis of whether or not the national culture of employees has any impact on the adherence to the code of ethics of multinational companies operating in Ghana. Again the paper will also find out if the orientation given to the employees and external partners before they begin their work with the companies has any bearing on the ability of the companies to be compliant. With the onset of increase in Global trade agreements in a highly competitive Modern-day business environments, multinational companies in all fields in the near future are expected to come under a lot of pressure to do more in operating an ethical business. Be it environmental ethics, financial ethics, accounting ethics, social ethics or communication ethics etc. A lack of ingrained corporate ethics has often come with serious attendant Consequences.

It is the reason why a lot of multinational or transnational companies spend a lot of time and resources to make sure their ethical policies are constantly reviewed. Part of what organizations have to deal with is about the challenge of this phenomenon and its managerial implications for crosscultural management.

Dealing with this is the aspect of putting in measures to ensure culturally sensitive ethical policies that can be embraced by all employees and external partners irrespective of their cultural background.

\section{Literature review}

Ghana is located in West Africa on the Gulf of Guinea, bordering with Togo in the east, the Ivory Coast in the west and Burkina Faso on the northern border. It is a former British colony and was the first country in the sub-Saharan area to gain its independence in 1957. Ghana has many different population groups, characterized by diverse socio-cultural beliefs and practices.

Ghanaian business culture is hierarchical and people gain respect as a result of age, experience, wealth and their position within a company. Senior business people tend to be in charge of making decisions in the best interests of their company. Godiwalla and Damanpour (2016) argues that many 
scholars agree on the need for ethical and social responsibilities issues management to be integrated in strategic management decision making at the highest level in the structure of the organization, that there should be more effective and sustainable social responsibilities pro-grams, and that there is the issue of duality of global versus local considerations for ethical and social responsibilities programs.

Here it is posited that good social responsibility is good business, that the good will and reputation of ethical and socially responsible organizations will win in the long run and MNCs will earn the public's respect and admiration.

\section{National culture}

Professor Geert Hofstede conducted one of the most comprehensive studies of how values in the workplace are influenced by culture. He defines culture as "the collective programming of the mind distinguishing the members of one group or category of people from others". Nations across the globe are distinct and unique from their respective cultures and so are organizations too distinctive and unique from their cultures. It can easily be noticed that people are shaped in the heart of national culture to carry their formed values as handed down by generations. Cultural differences have considerable impact on both the personal and corporate spheres of society.

\section{Ghana}

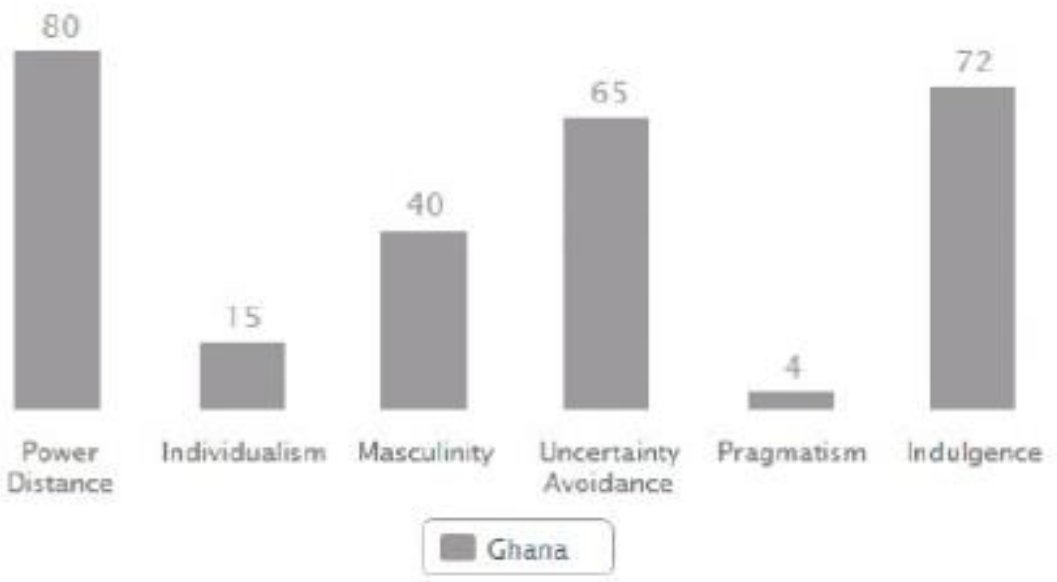

Figure 1. Hofstede cultural dimension data for ghana

\section{Organizational culture}

According to Enginoglu and Arikan (2016) corporate culture emerges through both formal and informal interactions between individuals. Ouchi (1981) stresses the importance of the kind of philosophy behind corporate strategies whereas Van Maanen (1976) asserts that informal groupings in the organization make it easy to spot what behaviors are favored or not. As the company and the culture with which it lives in evolve, favorable patterns of behavior that dictates what is acceptable or not naturally emerges.

Quinn Mill (1993) posits that organizational culture falls along the internal/external influences and control/flexibilities influences divides. Organizations that fall between internal influence focus, emphasizes integration, information management, communications, while as those that falls within the external influence focus emphasizes growth, resource acquisition and interaction between the external environments.

Once these patterns of behavior get fixed and become more stable, then newcomers as well as new modes of behavior are more likely to be influenced by and to adapt to these already existing behaviors rather than influencing the old ones and change them. 
Organizational culture analysis implies interaction influences between the organizations and the cultural environment where they are located. "The environment in which business organizations operate and executives' values and styles all interact to influence the performance of today's business" (Yasin, Alavi, \& Zimmerer, 2002 as cited by Gjuraj, E. (2013)).

Gjuraj continues to make the assertion that as a social construct culture is part of everyone within a given organization. It cannot be dressed or undressed when humans come out or in an organization. They will carry on their national culture into organizational environment. It is going to be easy at homogenous environment with people sharing the same national culture, but it is going to become complicated with people speaking different spoken and body languages, sharing different values and norms, coming from different historical and geographical developments, and celebrating different national and religious feast.

\section{Cultural diversity management and ethics}

According to Rufei and Jianchao (2010) culture is a complex issue in some fields such as sociology, anthropology and now become a hot topic in management. "Culture is the pattern of takenfor-granted assumptions about how a given collection of people should think, act and feel as they go about their daily affairs" (Joynt and Warner, 1996).

In Ghana and probably in most other places, there are some distinguishing factors that make up the differences among the ethnic groups which include language, belief systems, history, tales, legends, social organisations, physical environment, and customs. Several contributions are devoted in this area by some authors, such as Hofstede (1997), Hall (1976, referred to by Richardson and Smith, 2007), GLOBE (2004). Cross cultural management mainly focuses on the behavior of people from different culture working together as a group or an organization (Adler, 1983). Most of cross-cultural management study aims at dealing with the issue of organizational behavior, such as leadership style, motivational approaches, strategy, organizational structure (Morden, 1995; Elenkov, 1998). Three aspects are discussed in this study as follows, communication system, management style, and staff behavior.

According to Martin, G. (2014), Cultural diversity in the workplace has grown as a trend over the passage of time with the increase of globalization in the world. One positive effect is that employees belonging to different cultures usually have different ways of thinking and can thus analyze a matter at hand from a variety of perspectives. This is hard to achieve when employees belonging to the same culture are asked to analyze the same matter.

Cultural diversity has been defined as the quality of having diverse or different cultures as opposed to monoculture. It also means having different cultures that give respect to one another's differences and living in harmony.

A renowned sociology professor once stated that cultural diversity is the state of having a mind and a heart that acknowledges and accepts values and even celebrates the various ways people live and interact with one another. In its rich diversity, culture has intrinsic value for development as well as social cohesion and peaceful co-existence. Cultural Diversity has the potential of a powerful tool and a driving force for economic development and the fulfilment of intellectual, emotional, moral and spiritual life.

It is argued that countries that recognise the strength of their cultural diversities and exploit the advantages thereof stand the greater chance of socio-economic development.

According to UNESCO publication on Universal Declaration of Cultural Diversity (2001) the acceptance and recognition of Cultural Diversity by individuals and societies particularly through interactive use of the Media and ICT are conducive to building dialogue among civilisations and cultures, as well as fostering respect and mutual understanding.

\section{Organizational/Business ethics}

Ethics is defined as the process of distinguishing the right and good from the wrong and bad, and they imply a moral duty to pursue the good and the right. Business ethics are concerned with the good or right and the bad or wrong behavior in the business context. International business ethics apply to the varying business ethical issues in diverse country cultures (Godwila and Damanpour 2006). In 
some cases, failures in the overseas business of MNCs setting most frequently result from an inability to understand and adapt to foreign ways of thinking and acting rather than from technical or professional incompetence.

Additionally these organizations engage in a collective workplace managers and employees of all levels, with different backgrounds and national culture experiences. Thus each of them is a product of a unique culture. From his personal experience as a consultant in joint companies located in the developing countries such as Africa, Asia or Middle East Banutu-Gomez states that: "lack of skills in managing cultural differences causes conflict between leaders, managers and staff who originate from different cultures. Lack of understanding of cultural differences can cause serious miscommunication, which can hinder the growth and the productivity of an organization or company." (2002, p. 29 as cited by Gjuraj, E. (2013).

An important concern in strategic management in dealing with ethical and socially responsible conduct of a multinational corporation (MNC) is how to make sure all their employees adhere to it. Ethical conduct, usually beyond the legal conduct, has become a socially accepted norm for MNCs in most countries. Expectations of both ethical conduct and socially responsible conduct can vary in cultures of different countries. Codes of ethics are compilations of "written, distinct, and formal documents which consist of moral standards used to guide employee and corporate behavior" (Schwartz, 2001b; as cited by Enginoglu, and Arikan, 2016).

\section{Employee orientation}

Kat Kadian-Baumeyer (2017) argues that the function of new employee orientation introduces a new employee to the company, its policies, the coworkers and the job itself. Its characteristics include introducing the employee to the company's culture, roles and responsibilities, job description and other important things an employee will need to know.

However, it appears that orientation is a process and not a one-time event. The notion that orientation is an event for new employees is not appropriate because organizational orientation is now a life-long process for all employees. For new employees, it's a training program but for all employees, it's supposed to be continuous learning process.

The corporate management team should define and communicate the purpose of the business ethics program as early as possible. Responsible management recognizes that an effective business ethics program touches every decision and activity of the enterprise. This if integrated into the corporate culture influences patterns of thought, choice, and action that subtly shape the organizational culture of the enterprise. The business ethics program should be based on the core beliefs of the enterprise and should reflect an approach or orientation that will resonate with employees and other stakeholders.

\section{Organizational orientation as a continuous process}

Gary Weaver, Linda Trevino and Philip Cochran argue that ethics training programs vary from firm to firm partly because of the differences in external pressures and the vision of the top managers within the firm.

Some specific goals recommended by LeClair and Ferrel (2000) include the following:

- Provide the necessary tools needed by employees to understand the ethical-decision making process. This could include an explanation of specific terms and the rationale behind the ethical focus.

- Give the employees an opportunity to access the ethical priorities.

- Explain the procedure used when the employee violate the ethical standards established by the firm.

- Giving the opportunity for employees to be able to identify ethical programs based on the firm's ethical standards.

- Increase the level of sensitivity of employees' views pertaining to specific ethical issues.

- Enhance the ability of employees to increase their level of individual reflection as it relates to ethical issues. 
- Create a strong, positive ethical work climate in which ethical support systems and codes are in place within the firm.

\section{Methodology and data}

The methodology used was putting together some literature review from several researchers with synthesis of knowledge. The use of Secondary data by reading, summarizing and synthesizing other research materials was employed to deal with the problem statement. Hofstede statistically analyzed over 100,000 questionnaires which measured the values of employees at IBM in over 50 countries. In the original version of his model four independent dimensions were identified that could be used to characterize cultures on a national scale (Hofstede, 1980).

\section{Discussion}

Hofstede's six dimension model on culture is undoubtedly the most influential model of culture. Hofstede defines culture as, "the collective programming of the mind that distinguishes the members of one human group from those of another. Culture in this sense is a system of collectively held values" (Hofstede, 1981). Hofstede's model has been used in this research due to the inclusion of Ghana in his ground breaking culture research.

\section{Explanations based on hofstede's cultural dimensions}

Based on Hofstede's power distance Index, Ghana is in the league of cultures which scores high on power distance. According to Hofstede, subordinates in cultures with high power distance scores are prone to follow what their superiors tell them to do unlike in cultures with smaller power distances (Hofstede, 2010 pp73-74). In this regard, most Ghanaian employees will usually not challenge the status quo of foreign business ethics imposed on them by managers of the multinational firms they work for. They will usually follow the culture of the organization.

Ghana again belongs to a culture which is more collectively orientated as opposed to that of most multinational corporations which has individualist culture. Collectivist cultures tend to agree and flow with the opinions of their group rather than their own personal opinion. This makes it easier for the senior managers to implement ethical programs through the middle level managers who are usually Ghanaians.

Employees in Ghana come from a culture with a high power distance index and this tend to impact on the reason for the low uncertainty avoidance index. This tends to make it easier for Ghanaian employees to obey and adhere to company rules and regulations which are normally the code of conduct laid down by organizations.

From previous research findings analyzed so far especially from Professor Hofstede and GLOBE, much has been identified as some of the practices and orientations which appear to characterize Ghanaian business cultural environment. The objective of this capstone project as stated earlier in the problem statement was an exploratory exercise to analyze national culture, business ethics and whether employees are well oriented to behave ethically.

This has particular relevance for ensuring a differentiated approach to support interventions targeted at improving the ethical business culture or strengthening business capacity to be ethical.

Clearly, it comes across that the Ghanaian business ethical culture is one that is in a state of development with many multinational organizations and other local businesses struggling with the interface between the national culture and corporate ethics. There are clear difficulties with advocacy, corruption, use of contract and lack of a partnership culture. Regulatory support for business and weaknesses in service culture is also a problem.

In conclusion, it is evident that the impact of Ghanaian national cultural ethics on corporate ethics can be both favorable and unfavorable. From the cultural dimension research conducted so far coupled with the weak nature of some of our institutions, it appears MNCs from more stricter countries of origin tend to enforce some form of ethical standards to adhere to their home ethical laws requirements

Inasmuch as the home office is concerned with core ethical and social responsibility values, the diverse cultural values and orientations of the many foreign subsidiaries make it further challenging to 
the to come up with a common set of values. Diversity issues in Ghana often make the work of multinational company managers more complex, and challenging and interesting.

\section{Conclusion}

The aim of this paper was to contribute to the understanding of how the Ghanaian culture either support or impede the formulation and implementation of corporate ethics in organizations. Again it came to light from previous studies in the field that corporate culture of multinational organizations are not affected negatively by the national culture of Ghana when it comes to dealing with employees.

Again, considering the studies done so far by Hofstede and the GLOBE project, most of these multinational firms come with well-established business and corporate culture which tends to rather influence the culture of the employees and thereby the larger community and families.

\section{References}

[1]. Akatey N. (2014) "The relevance of cultural diversity and national development"

[2]. Alireza Nazarian, Zahir Irani, \& Maged Ali "The Relationship between National Culture and Organizational Culture: The Case of Iranian Private Sector Organizations" Journal of Economics, Business and Management, Vol. 1, No. 1, February 2013

[3]. Enginoglu, D \& Arikan, C. International Journal of Research in Social Sciences March. 2016. Vol. 6, No.5 www.ijsk.org/ijrss

[4]. Ferrell, O. C., \& Fraedrich, J. (2015). Business ethics: Ethical decision making \& cases. Nelson Education. [5]. Furber, A; Smith, S.D \& Crapper, M (2012) A case study of the impact of cultural Differences during a construction project in Ghana In: Smith, S.D (Ed) Procs 28 th Annual ARCOM Conference, 3-5 September 2012, Edinburgh, UK, Association of Researchers in Construction Management, 553-562.

[6]. Gary R. Weaver, G., TreviÑo, L., \& Cochran, P. "Integrated and Decoupled Corporate Social Performance: Management Commitments, External Pressures, and Corporate Ethics Practices" sourced from http://amj.aom.org/content/42/5/539.full

[7]. Gjura, Edlira (Tukaj), "The importance of national culture studies in the organizational context" European Scientific Journal April 2013 edition vol.9, No.11 ISSN: 1857 - 7881 (Print) e - ISSN 1857- 7431

[8]. Godwilla, Y. \& Damanpour, F. "The MNCS Global Ethics and Social Responsibility: A Strategic Diversity Management Imperative" Journal of Diversity Management - 2006 Volume 1, Number 2

[9]. Hofstede, G. (2001). Culture's Consequences. Comparing values, behaviors, institutions and Organizations across nations, Thousand Oaks CA: Sage.

[10]. https://www.cleverism.com/understanding-cultures-people-hofstede-dimensions/

[11]. http://www.trade.gov/goodgovernance/adobe/bem_section_2/chapter_4.pdf Date sourced: 1/5/2017

[12]. http://study.com/academy/lesson/new-employee-orientation-function-characteristics.html

[13]. http://www.ccsenet.org/journal/index.php/ijbm/article/\%20viewFile/10431/7448

[14]. http://unesdoc.unesco.org/images/0012/001271/127162e.pdf

[15]. Kadian-Baumeyer, K. (2017) "New Employee Orientation: Function \& Characteristics"

[16]. Martin, Gillian. (2014), Journal of Diversity Management - December 2014 Volume 9, Number 2

[17]. Mooij M., \& Hofstede G. (2010). The Hofstede model Applications to global branding and advertising strategy and research. International Journal of Advertising, 29, 85-110.

[18]. Rufei He \& Jianchao Liu (2010) "Barriers of Cross Cultural Communication in Multinational Firms"

[19]. The GoG-UNFPA $5^{\text {th }}$ Country Programme, 2 006-2010

[20]. Thorne LeClair, D. \& Ferrell, L. Journal of Business Ethics (2000) 23: 313. doi:10.1023/A:1006266526120

[21]. Weaver, G. \& TrevinAo, L "The role of human resources in ethics/compliance management a fairness perspective" Human Resource Management Review 11 (2001) www.HRmanagementreview.com Quinn Mill, D. (1993) Rebirth of Corporation, New York, Wiley. 